\title{
Los delirios de negación según Cotard y Séglas
}

Como señalan Haustgen y Bourgeois, hace algo más de un siglo el joven alienista parisino J. Séglas (1856-1939) publicó a lo largo de pocos años una serie de obras magistrales, destinadas a establecer de forma perdurable en Francia los cuadros de la clínica psiquiátrica ${ }^{1}$. A los Trastornos del lenguaje en los alienados sucedieron tres años más tarde las Lecciones clínicas sobre las enfermedades mentales y nerviosas. Sólo dos años después apareció la famosa monografía sobre $E l$ delirio de negación. El colofón de toda esta obra fue el capítulo «Semiología de las afecciones mentales» del Tratado de Gilbert Ballet. En el intervalo, un número impresionante de artículos (se ha estimado que totalizan ciento treinta) fue publicado por Séglas, tocando los más diversos terrenos de la clínica. Sin embargo, a pesar de que su nombre es muy frecuentemente citado por sus contemporáneos, esos trabajos y monografías no han sido reeditados, y hasta 1950 no comienzan a aparecer artículos un poco consecuentes sobre Séglas ${ }^{2}$. Aún hoy no disponemos de una bibliografía exhaustiva y detallada sobre sus escritos, y las publicaciones anglo-americanas rara vez los mencionan, si exceptuamos a Germán Berrios $^{3}$.

Respecto a El delirio de negación, Séglas se inspira en las descripciones de Jules Cotard (1840-1889), quien destacó por su agudo sentido clínico y su sólida cultura médica y filosófica. A decir de Jules Falret, estas aptitudes le habían preparado «para el estudio de los alienados y de la psicología morbosa. Había profundizado en sus múltiples manifestaciones con una claridad notable, ya bien patente desde su primer trabajo sobre patología mental, el artículo «Locura» del Diccionario enciclopédico de las ciencias médicas (1877). Tras ese estudio general, Cotard se dedicó más específicamente a la cuestión de las melancolías, una de las más complejas de la patología mental» ${ }^{4}$. En 1880 presentó en la Sociedad Médicopsicológica un caso de «Delirio hipocondriaco en una forma grave de la melancolía ansiosa». A través de sucesivas publicaciones («Sobre el delirio de negación», «Pérdida de la visión mental en la melancolía ansiosa», «Sobre el delirio de enormidad» y el artículo «Hipocondría» del Diccionario Dechambre), vemos precisarse progresivamente el cuadro clínico de esos estados en que los enfermos niegan la existencia misma de sus órganos y hasta la de su cuerpo entero o la del mundo que les

\footnotetext{
1 Véase T. Haustgen y M. L. Bourgeois, «Le Dr. Jules Séglas (1856-1939), président de la Société Médico-Psychologique, sa vie et son oeuvre», Annales médico-psychologiques, 2002, vol. 160, n. ${ }^{\circ}$ 10, pp. 701-712.

2 Barbé, A., «Séglas», L'Encéphale, 1950, 39, pp. 335-345. Thefenne, D., Les troubles du langage parlé dans l'oeuvre de Jules Séglas, Tesis de Medicina (dirigida por el Prof. Morel), Caen, 1995.

3 Berrios, G. E., The History of Mental Symptoms, Cambridge, Cambridge University Press, 1996.

4 Jules FALRET, «Préface», en J. COTARD, Études sur les maladies cérébrales et mentales, París, J. B. Baillière, 1891, pp. V-XII.
} 
rodea, o por el contrario desarrollan temas delirantes de enormidad corporal, de culpa anonadante y de inmortalidad dolorosa.

Cotard mismo confiesa su aspiración de describir «al negador resaltando principalmente las diferencias y los contrastes que presenta respecto al persegui$d o »$, propósito que culmina en el cuadro que cierra su artículo «El delirio de negación» (1882). Siguiendo ese proceder espera individualizar una nueva y «verdadera enfermedad», la cual reagrupe síntomas asociados entre sí y se diferencie del resto por sus características y evolución. Al igual que unos años después propondrá Freud, Cotard destaca la importancia de la autoacusación, signo que por sí mismo basta para distinguir a este tipo de melancólicos ansiosos de los perseguidos; estos melancólicos se acusan a sí mismos, y lo hacen de una manera tan llamativa que consideran justo someterse al último suplicio, pues «se lo tienen bien merecido por sus crímenes». De conformidad con estas observaciones, establece dos grandes clases de melancólicos: los que se echan la culpa a sí mismos y los que acusan al entorno social. Pero el delirio de negación, de progresar, puede alcanzar ciertas proporciones «monstruosas» hasta culminar en una forma particular de delirio pseudomegalomaniaco o «delirio de enormidad», variante caracterizada por ideas de inmortalidad e inmensidad, a cuya descripción dedicó su artículo de 1888 «El delirio de enormidad».

A diferencia de la corriente principal, la que hermanaba la asociación natural de la melancolía y la manía, la orientación desarrollada por Jules Cotard recupera la simetría entre melancolía y paranoia (delirio de negación versus delirio de persecución). Para fundamentar esta oposición, inicialmente Cotard echa mano del análisis semiológico, en especial de la «fórmula del delirio», principio rector de su metodología. Así lo propone en el segundo párrafo de «El delirio de enormidad»: «Aunque el análisis de semejantes casos psicológicos sea delicado y el diagnóstico sea a menudo tortuoso, parece que la dificultad no haya de referirse a la apreciación de las propias ideas delirantes. Nos cuesta concebir que frente a una forma delirante, el clínico se sienta importunado y dude en calificarla de idea de persecución, idea melancólica o idea de grandeza. Da la sensación, repito, de que la idea, que ha sido expresada claramente por el enfermo, debe caracterizarse con la suficiente claridad por sí misma». A esta oposición semiológica inicial (ideas de negación versus ideas de persecución), Cotard irá paulatinamente añadiendo otras en la que se perfila la simetría melancolía-paranoia: en el terreno del carácter, tendencias autoacusadoras frente a tendencias heteroacusadoras; en el ámbito etiológico, fenómenos psicomotores en contraposición a fenómenos psicosensoriales.

Las descripciones de Cotard sobre el delirio de negación y el delirio de enormidad, dada la precisión de su análisis semiológico y lo llamativo de los temas delirantes, consiguieron de inmediato hacerse un hueco en el abigarrado territorio 
HISTORIA DE LA PSIQUIATRÍA

de la patología mental; en cambio, las explicaciones psicopatológicas de esa «enfermedad» melancólica -inspiradas en las concepciones neuropsicológicas de Charcot sobre las afasias-apenas le sobrevivirían, tanto las que creyó fundadas en la «pérdida de la visión mental» como las que, a última hora, pergeñó a partir de la oposición entre las lesiones funcionales psicosensoriales y las psicomotrices. Poco después de la prematura muerte de Jules Cotard, en su intervención en el congreso de Blois (1892), Emmanuel Régis propuso nombrar al delirio de negación Síndrome de Cotard, epónimo con el que honraba al psiquiatra que lo había descrito ${ }^{5}$. Sería esta perspectiva sindrómica la que terminaría imponiéndose, hecho al que contribuyó con sus numerosas aportaciones Jules Séglas.

Como la mayoría de los autores, también Séglas destaca el «dolor moral», singular manifestación a la que dedica numerosas reflexiones en las que lo compara con el dolor físico. A sus ojos, el melancólico es un enfermo «ingenioso en lo que concierne a atormentarse ${ }^{6}$. Sus discrepancias con Cotard no radican ahí, sino en la metodología que uno y otro emplean. Si para Cotard la «fórmula del delirio» bastaba para establecer las distinciones nosográficas, Séglas afirma que ésta «no es suficiente para caracterizar un estado mórbido» ${ }^{7}$, con lo cual las ideas de negación pierden su especificidad. Frente a la «fórmula del delirio», Jules Séglas propone investigar «la génesis de las ideas delirantes», guía que debe servir de elemento capital para el diagnóstico. Desde su punto de vista se trata de enfocar el conjunto clínico-evolutivo: «el diagnóstico completo debe contemplar siempre todos los otros síntomas [además del delirio], tanto los somáticos como los psíquicos, su modo de aparición, su sucesión, sus respectivas relaciones, así como la evolución del conjunto de la afección $»^{8}$.

De resultas de la aplicación de esta metodología, Séglas caracteriza la melancolía delirante por la naturaleza tormentosa de los temas delirantes; el trasfondo siempre presente del dolor, el sufrimiento y la inhibición mental; la insignificancia [humilité], la pasividad y la resignación; la extensión «centrífuga» de sus ideas, esto es, el temor de que sus allegados sufran las consecuencias de su desgracia o de su maldad; la actitud delirante de espera, destacada por Lasègue cuando propuso que el melancólico está a la espera de juicio, mientras que el perseguido ya

5 Véase AA. VV. Congrès de Médecine mentale de Blois, 1892. Una crónica de este congreso puede leerse en A. GIRAUD, «Le Congrès de médicine mentale à Blois», Annales Médico-psychologiques, 1892, 16, pp. 177-195; en especial pp. 179-183, donde se recoge la intervención de Camuset sobre el delirio de negación, y las réplicas, entre otros, de Régis y Séglas.

6 SÉGlas, J., Le délire des négations. Sémiologie et diagnostic, París, Masson, 1897, p. 92.

7 SÉGLAs, J. : «Le délire systématique primitif d'auto-accusation», Archives de Neurologie, 1899, VII, p. 443 .

8 SÉGlas, J.: Leçons cliniques sur les maladies mentales et nerveuses (Salpêtrière 1887-1894). Recueillies et publiées par le Dr. Henry Meigne, París, Asselin y Houzeau, 1895, p. 558. 
está condenado; el carácter retrospectivo que lleva al enfermo a buscar alguna falta cometida en el pasado que explique su situación actual; la presencia relativa de alucinaciones visuales frente a rareza de las auditivas. Tanto la melancolía simple como la delirante se asientan, según Séglas, en una alteración de la personalidad que se origina a consecuencia de modificaciones orgánicas, alteración que por sí misma es la causante del dolor moral, del que derivan las ideas delirantes (negación, hipocondría, culpa o condena).

A la par que Séglas fue desarrollando su concepción de la melancolía, la distancia con las descripciones de Cotard se agrandó. En su monografía Le délire des négations concluye que éste no constituye de ninguna manera y en ninguna circunstancia una enfermedad específica; por el contrario, esas ideas delirantes son sólo un síntoma que se encuentra en formas muy variadas de la alienación mental, de manera que por sí mismas no tienen nada de patognomónico. «El síndrome de Cotard -señala Séglas en las conclusiones de su monografía- se presenta la mayoría de las veces después de uno o varios accesos de melancolía, sobre todo ansiosa, y revistiendo la forma común. Indica, por lo general, un estado de cronicidad; la enfermedad tiende a pasar de intermitente, como era hasta entonces, a continua; no obstante, hay otros casos que pueden curar» ${ }^{9}$. Conforme a su concepción de la melancolía desarrollada en las Leçons cliniques entre 1887 y 1894, también las ideas de negación constituyen la manifestación de una alteración de la personalidad que sobreviene como efecto de modificaciones de la base orgánica (cenestesia) y de la esfera motriz y afectiva de la vida psíquica.

José María Álvarez

Fernando Colina Ramón Esteban

* Texto entresacado de la Presentación de J. Cotard y J. SÉGlas, Delirios melancólicos: negación y enormidad (Madrid, Ergon-Biblioteca de Los Alienistas del Pisuerga, 2008, pp. IX-XXVIII).

9 SÉGlas, J., Le délire des négations. Sémiologie et diagnostic, p. 222. 